This document is confidential and is proprietary to the American Chemical Society and its authors. Do not copy or disclose without written permission. If you have received this item in error, notify the sender and delete all copies.

\title{
Highly Compatible Hydroxyl-Functionalized Microporous Polyimide-ZIF-8 Mixed Matrix Membranes for Energy Efficient Propylene/Propane Separation
}

\begin{tabular}{|r|l|}
\hline Journal: & ACS Applied Nano Materials \\
\hline Manuscript ID & an-2018-00682g.R1 \\
\hline Manuscript Type: & Article \\
\hline Date Submitted by the Author: & $\mathrm{n} / \mathrm{a}$ \\
\hline Complete List of Authors: & $\begin{array}{l}\text { Ma, Xiao-Hua; King Abdullah University of Science and Technology, } \\
\text { Swaidan, Ramy; King Abdullah University of Science and Technology } \\
\text { Wang, Yingge; King Abdullah University of Science and Technology, } \\
\text { Advanced Membranes and Porous Materials Center, PSE Division } \\
\text { Hsiung, Chia-en; King Abdullah University of Science and Technology } \\
\text { Han, Yu ; KAUST, } \\
\text { Pinnau, Ingo; KAUST, }\end{array}$ \\
\hline
\end{tabular}




\title{
Highly Compatible Hydroxyl-Functionalized Microporous Polyimide-ZIF-8 Mixed Matrix Membranes for Energy Efficient Propylene/Propane Separation
}

\author{
Xiaohua Ma ${ }^{\mathrm{a}, \mathrm{b}}$, Ramy J. Swaidan ${ }^{\mathrm{a}, \mathrm{b}}$, Yingge Wang ${ }^{\mathrm{b}}$, Chia-en Hsiung ${ }^{\mathrm{b}}$, \\ $\mathrm{Yu} \mathrm{Han}^{\mathrm{b}}$, and Ingo Pinnau, ${ }^{\mathrm{a}, \mathrm{b} *}$ \\ ${ }^{\mathrm{a}}$ Functional Polymer Membranes Group, ${ }^{\mathrm{b}}$ Advanced Membranes and Porous Materials Center, \\ Division of Physical Sciences and Engineering, King Abdullah University of Science and \\ Technology (KAUST), Thuwal 23955-6900, Kingdom of Saudi Arabia \\ Corresponding Author \\ *ingo.pinnau@kaust.edu.sa
}

\section{Keywords}

ZIF-8, intrinsically microporous polyimide, hydroxyl-functionalization, mixed-matrix membrane, propylene/propane separation 


\section{ABSTRACT}

Mixed-matrix membranes composed of mechanically strong, solution-processable polymers and highly selective ultramicroporous fillers (pore size $<7 \AA$ ) are superior candidate membrane materials for a variety of energy-intensive gas separation applications because of their structural tunability to achieve enhanced gas permeability and gas-pair selectivity. However, their industrial implementation has been severely hindered because inefficient compatibility of the polymer matrices and crystalline fillers results in poorly performing membranes with low filler capacity and interfacial defects. Herein, we report for the first time a unique strategy to fabricate highly propylene/propane selective mixed-matrix membranes (MMMs) composed of a hydroxyl-functionalized microporous polyimide (PIM-6FDA-OH) and an ultramicroporous, strongly size-sieving zeolitic imidazolate framework (ZIF-8). Excellent compatibility between PIM-6FDA-OH and ZIF-8 with selective filler loading up to $65 \mathrm{wt} \%$ resulted from N...O-H induced hydrogen bonding as evidenced by Fourier-transform infrared spectroscopy (FT-IR) and X-ray photoelectron spectroscopy (XPS). The newly developed MMMs demonstrated unprecedented mixed-gas performance for $\mathrm{C}_{3} \mathrm{H}_{6} / \mathrm{C}_{3} \mathrm{H}_{8}$ separation and outstanding plasticization resistance of up to at least 7 bar feed pressure. The reported fabrication concept is expected to be applicable to a wide variety of $\mathrm{OH}$ functionalized polymers and alternative tailor-made imidazolate framework materials designed for MMMs to achieve optimal gas separation performance. 
Propylene is the second largest produced organic chemical with an annual global production capacity of approximately 100 million tons in $2016 .{ }^{1}$ It is primarily used for synthesis of polypropylene, propylene oxide, acrylonitrile, cumene, acrylic acid, isopropanol and others. ${ }^{1,2}$ At a propylene price of $\sim 700-1000$ USD/ton, propylene represents a total market value of $\sim 100$ billion USD/year. The final step in the production of propylene is large-scale distillation from propane in a $\mathrm{C} 3$-splitter at $\sim 20$ bar and $\sim 50{ }^{\circ} \mathrm{C}$.,4 Because of the small difference in relative volatility between propylene and propane $(\sim 1.08-1.12)$, distillation is performed in columns over $200 \mathrm{ft}$ tall containing over 150 trays and operating at reflux ratios $>10$, thereby making it one of the most energy-intensive separation processes in the chemical process industry. ${ }^{5-7}$ Membrane technology offers a potential alternative to the conventional distillation process for propylene/propane separation. The current sales of membrane-based gas separation systems is in the range of US\$ 1-1.5 billion per year with a 90\% market share for: (i) hydrogen recovery from various off-gas streams, (ii) onsite nitrogen production from air, (iii) carbon dioxide removal from natural gas, and (iv) olefin recovery from nitrogen-containing petrochemical vent gas streams. ${ }^{8}$ However, current commercial polymer membrane materials used in these processes suffer from several severe drawbacks for viable propylene/propane separation: (i) low $\mathrm{C}_{3} \mathrm{H}_{6}$ permeability $\left(<10\right.$ barrer -1 barrer $=1 \times 10^{-10}$ $\left.\mathrm{cm}^{3}(\mathrm{STP}) \mathrm{cm} \mathrm{cm}^{-2} \mathrm{~s}^{-1} \mathrm{cmHg}^{-1}\right)$, (ii) low $\mathrm{C}_{3} \mathrm{H}_{6} / \mathrm{C}_{3} \mathrm{H}_{8}$ selectivity $(<10$ ), and (iii) poor plasticization resistance under challenging high-pressure mixed-gas conditions that leads to reduction of selectivity. ${ }^{9,10}$ One of the most promising membrane materials for propylene/propane separation is based on a chemically and thermally stable ultramicroporous zeolitic imidazolate framework (ZIF-8) with sodalite topology made by synthesis of zinc nitrate hexahydrate and 2-methylimidazole. ${ }^{11}$ This ultramicroporous material is characterized by external aperture windows of $3.4 \AA$ as determined by single-crystal XRD. Interestingly, recent work reported a significantly larger effective pore size of 4.0-4.2 $\AA$ due to some framework flexibility in ZIF-8, ${ }^{12-14}$ providing the material with excellent molecular sieving properties for propylene/propane separation. ${ }^{15}$ However, fabrication of defect-free pure ZIF-8 membranes is difficult

\section{INTRODUCTION}


due to the crystalline nature of the material which leads to inherent brittleness and intercrystalline packing defects. One approach to overcome these deficiencies is to prepare mixed-matrix membranes (MMMs) which are composed of a solution-processible, mechanically strong polymer with gas transport properties preferably located on or above the permeability/selectivity performance trade-off curve for a specific application and an ultramicroporous filler that can boost both gas permeability and gas-pair selectivity. ${ }^{16-}$ ${ }^{18}$ This concept has been applied to ZIF-8-based MMMs for a variety of gas separation applications, ${ }^{20-22}$ including propylene/propane separation. ${ }^{23,24}$ The most important challenges in the formation of advanced mixed-matrix membranes are: (i) elimination of interfacial defects that arise from poor compatibility between the polymer matrix and the highly selective ultramicroporous filler and (ii) limitations in the maximum filler loading for MMMs with sufficiently high mechanical strength. ${ }^{25}$ A recent study demonstrated that ZIF-8 nanoparticles coated with polydopamine (PD) enhanced their compatability with a Tröger's base derived polyimide matrix due to interactions by hydrogen bonding of the orthodihydroxyl groups in the PD and the nitrogen of the imidazole in ZIF- $8 .^{26}$ The resulting MMMs demonstrated moderately improved gas separation properties but no propylene/propane permeation data were reported and the ZIF-8 content was limited to only $30 \mathrm{wt} \%$.

This work reports the preparation and exceptional propylene/propane separation properties of a novel MMM type made from a solution-processable microporous dihydroxyl-functionalized polyimide (PIM6 FDA-OH $)^{27}$ and ZIF-8 as highly permeable and selective ultramicroporous filler (Figure 1a). PIM6FDA-OH was selected as the matrix material for ZIF-8 nanocomposite membranes because of its hydroxyl-functionality for enhanced compatibility and excellent gas transport properties with propylene permeability of 3.5 barrer combined with $\mathrm{C}_{3} \mathrm{H}_{6} / \mathrm{C}_{3} \mathrm{H}_{8}$ selectivity of 30 , which places its performance above the polymer permeability/selectivity upper bound reported by Burns and Koros. ${ }^{28,29}$ 


\section{EXPERIMENTAL SECTION}

Materials. Basolite ${ }^{\circledR}$ Z1200 (2-methylimidazole zinc salt, ZIF-8) was obtained from Sigma-Aldrich and dried at $200{ }^{\circ} \mathrm{C}$ for $24 \mathrm{~h}$ before use. The hydroxyl-functionalized microporous polyimide (PIM6FDA-OH) was prepared by polycondensation reaction of 4,4'-(hexafluoroisopropylidene)diphthalic anhydride (6FDA) with 3,3,3',3'-tetramethyl-1,1'-spirobisindane-5,5'-diamino-6,6'-diol (SBIDA) as previously reported by our group. ${ }^{27}$ The monomer 4,4'-(hexafluoroisopropylidene)diphthalic anhydride (6FDA, 99\% Aldrich-Sigma) was purified by sublimation before use. All materials and solvents for monomer and polymer syntheses, bisphenol A, methylsulfonic acid, dichlorotin hydrochloride solution, sodium carbonate, dichloromethane, ethyl acetate, ligroin, nitric acid, pyridine, anhydrous tetrahydrofuran (THF) and $N$-methylpyrrolidone were also obtained from Aldrich-Sigma. The molecular weight $\left(\mathrm{M}_{\mathrm{n}}\right)$ and polydispersity index (PDI) of PIM-6FDA-OH obtained by GPC (Agilent 1200) were $8.54 \times 10^{4} \mathrm{~g} \mathrm{~mol}^{-1}$ and 1.94 , respectively.

Membrane Preparation. Mixed-matrix membranes (MMMs) reported in this work consisted of a dihydroxyl-functionalized, intrinsically microporous polyimide (PIM-6FDA-OH) and a zeolytic imidazolate framework (ZIF-8). The MMMs were made by the following procedure: First, dried commercial ZIF-8 (30, 60, 80, 100 and $120 \mathrm{mg}$, respectively) was separately placed in vials and then dispersed in $3 \mathrm{~mL}$ anhydrous THF using an ultrasonic horn (Vibra-Cell, Sonics \& Materials Inc.) The mixture was sonicated for 30 min with an energy intensity of 50\% and $3 \mathrm{~s}$ intervals. Second, PIM-6FDA$\mathrm{OH}$ powder (170, 140, 120, 100 and $80 \mathrm{mg}$, respectively) was slowly added to the mixture and placed on a roller mixer for $24 \mathrm{~h}$. Based on weighted amounts of PIM-6FDA-OH and ZIF-8, the stock suspensions contained 15, 30, 40, 50, and $60 \mathrm{wt} \% \mathrm{ZIF}-8$, respectively. Third, the polymer concentration of each suspension was adjusted to $\sim 5 \mathrm{wt} \%$ by gently flushing with $\mathrm{N}_{2}$ to partially remove THF. Thereafter, the more concentrated suspensions were placed again on a roller mixer for $24 \mathrm{~h}$ to ensure homogeneous mixing of PIM-6FDA-OH and ZIF-8 particles in THF. Finally, isotropic films were obtained by casting the suspensions on glass plates with a doctor blade. The cast films were placed in an oven and the THF 
was removed by continuous flushing with nitrogen at room temperature for $8 \mathrm{~h}$. The resulting mixedmatrix membranes were further dried at $250{ }^{\circ} \mathrm{C}$ for $24 \mathrm{~h}$. Prior to gas permeation testing, complete solvent removal from the films was confirmed by TGA analysis under $\mathrm{N}_{2}$ atmosphere. Films with thicknesses of 40-60 $\mu \mathrm{m}$ were used for gas permeation experiments.

Materials Characterization. Thermal gravimetric analysis (TGA) was carried out with a TGA Q5000 equipped with a thermal analyzer both in $\mathrm{N}_{2}$ and air atmosphere; the samples were heated from room temperature to $800{ }^{\circ} \mathrm{C}$. Fourier transform infrared spectroscopy (FT-IR) spectra were aquired using a Varian 670-IR spectrometer. Wide-angle X-ray diffraction (WXRD) was conducted on a Bruker D8 Advance diffractometer from 6 to $50^{\circ}$ at a scanning rate of $0.5^{\circ} \mathrm{min}^{-1}$. X-ray photoelectron spectroscopy (XPS) of PIM-6FDA-OH, ZIF-8 and the mixed-matrix membrane containing 33 wt\% ZIF-8 was performed with a Kratos Axis Ultra DLD spectrometer equipped with a monochromatic Al K $\alpha$ X-ray source $(\mathrm{h} v=1486.6 \mathrm{eV})$ operating at $150 \mathrm{~W}$, a multichannel plate, and delay line detector under $1 \times 10^{-9}$ Torr vacuum. Energy-filtered transmission electron microscopy (EF-TEM) was performed on a FEI Titan ST electron microscope equipped with a GIF system operated at $300 \mathrm{kV}$. ZIF-8 particles size distribution was determined by dynamic light scattering measurements using a Zetasizer Nano ZS from Malvern Pananalytical. The BET surface area of ZIF-8 powder was measured by $\mathrm{N}_{2}$ adsorption at $-196{ }^{\circ} \mathrm{C}$ (Micrometrics ASAP 2020 with micropore option); the sample was degassed at $150{ }^{\circ} \mathrm{C}$ for $12 \mathrm{~h}$ before testing. Dynamic mechanical stress-strain curves of PIM-6FDA-OH and the ZIF-8-based MMMs were measured using a dynamic mechanical analyzer (DMA, TA Instruments Q800). The samples were kept at $25^{\circ} \mathrm{C}$ for one minute and then ramped at $3 \mathrm{~N} / \mathrm{min}$ to $18 \mathrm{~N}$.

Pure-Gas Permeation Measurements. The pure-gas permeability values of the membranes for $\mathrm{C}_{3} \mathrm{H}_{6}$ and $\mathrm{C}_{3} \mathrm{H}_{8}$ were determined at 2 bar upstream pressure and $35{ }^{\circ} \mathrm{C}$ using the constant-volume/variablepressure method. The membranes were degassed in the permeation system on both sides under high vacuum at $35{ }^{\circ} \mathrm{C}$ for at least $24 \mathrm{~h}$. The increase in permeate pressure with time was recorded by a MKS Baratron transducer. The gas permeability was determined by: 


$$
P=10^{10} \frac{V_{d} l}{P_{u p} A R T} \frac{d p}{d t}
$$

where $P$ is the permeability (barrer) -1 barrer $=10^{-10} \mathrm{~cm}^{3}(\mathrm{STP}) \mathrm{cm} \mathrm{cm}^{-2} \mathrm{~s}^{-1} \mathrm{cmHg}^{-1}, p_{u p}$ is the upstream pressure $(\mathrm{cmHg}), d p / d t$ is the steady-state permeate-side pressure increase $\left(\mathrm{cmHg} \mathrm{s}^{-1}\right), V_{d}$ is the calibrated permeate volume $\left(\mathrm{cm}^{3}\right), l$ is the membrane thickness $(\mathrm{cm}), A$ is the effective membrane area $\left(\mathrm{cm}^{2}\right), T$ is the operating temperature $(\mathrm{K})$, and $R$ is the gas constant $\left(0.278 \mathrm{~cm}^{3} \mathrm{cmHg} \mathrm{cm}^{-3}(\mathrm{STP}) \mathrm{K}^{-1}\right)$. The diffusion coefficient $D\left(\mathrm{~cm}^{2} \mathrm{~s}^{-1}\right)$ was calculated by $D=P / S$ using the solubility coefficient $S$ obtained from direct gravimetric sorption measurements at 2 bar and $35^{\circ} \mathrm{C}$. The ideal selectivity of $\mathrm{C}_{3} \mathrm{H}_{6} / \mathrm{C}_{3} \mathrm{H}_{8}$ was obtained by the permeability ratio, $\alpha=P C_{3} H_{6} / P C_{3} H_{8}$.

Mixed-Gas Permeation Experiments. Pressure-dependent mixed-gas testing of the mixed-matrix membranes was performed with a $\mathrm{C}_{3} \mathrm{H}_{6} / \mathrm{C}_{3} \mathrm{H}_{8}(50: 50 \mathrm{~mol} \%)$ feed mixture from 2 to 7 bar at $35{ }^{\circ} \mathrm{C}$. A stage-cut (permeate to feed flow rate) of 0.01 was used to avoid concentration polarization. The permeate composition was determined using a calibrated gas chromatograph (Agilent 3000A Micro GC) equipped with thermal conductivity detectors (TCD). The mixed-gas permeability of component $i$ was determined via:

$$
P_{i}=10^{10} \frac{y_{i} V_{d} L}{x_{i} p_{u p} A R T} \frac{d p}{d t}
$$

where $y_{i}$ is the molar fraction of component $i$ in the permeate and $x_{i}$ is the molar fraction of component $i$ in the feed. The mixed-gas permselectivity was calculated by:

$$
\alpha_{C 3 H 6 / C 3 H 8}=\frac{y_{C 3 H 6} / y_{C 3 H 8}}{x_{C 3 H 6} / x_{C 3 H 8}}
$$

Gravimetric Sorption. $\mathrm{C}_{3} \mathrm{H}_{6}$ and $\mathrm{C}_{3} \mathrm{H}_{8}$ sorption data of the mixed-matrix membranes were obtained gravimetrically using an IGA-003 (Hiden Isochema) at 2 bar and $35{ }^{\circ} \mathrm{C}$ with samples of $30 \sim 50 \mathrm{mg}$. All samples were degassed for at least $24 \mathrm{~h}$ until constant weight was obtained before starting the sorption run. Each sorption run was repeated three times to ensure data reproducibility. 


\section{RESULTS AND DISCUSSION}

Structural Properties. Commercially available ZIF-8 powder (Basolite Z1200, Sigma-Aldrich) was used for the preparation of PIM-6FDA-OH-based mixed-matrix membranes. The Brunauer-Emmett-Teller (BET) surface area of the Basolite Z1200, measured by nitrogen adsorption at $-196{ }^{\circ} \mathrm{C}$ up to 1 bar (Figure $\mathrm{S} 1$ ), was $1406 \mathrm{~m}^{2} \mathrm{~g}^{-1}$. The particle size distribution of ZIF-8 was determined by light scattering of a suspension in ethanol using a Malvern Zetasizer ZS. Two main fractions were identified of which 96.5\% contained an average particle size of $309 \mathrm{~nm}$ and $3.5 \%$ had an average size of $782 \mathrm{~nm}$ (Fig S2). TEM images of Basolite Z1200 particles are shown in Figure S3, which confirmed the particles size range of ZIF-8.

Mixed-matrix membranes were obtained with up to $65 \mathrm{wt} \%$ ZIF-8 loading in PIM-6FDA-OH by suspension casting as described in the experimental section (Figure 1a). All MMMs were heated to 250 ${ }^{\circ} \mathrm{C}$ for $24 \mathrm{~h}$ prior to mechanical and gas permeation testing to ensure complete removal of solvent either trapped in the polymer matrix or inside the ZIF-8 cages as confirmed by thermal gravimetric analysis (TGA). Excellent compatibility between ZIF-8 and the PIM-6FDA-OH polyimide matrix is clearly visible in the TEM cross-section images shown in Figure $1 \mathrm{~b}$ and Figure S4. The ZIF-8 particles were well distributed in the PIM-6FDA-OH polyimide matrix up to $52 \mathrm{wt} \%$ loading; at higher ZIF-8 content of 65 $\mathrm{wt} \%$, agglomeration is clearly visible, but no interfacial gaps were detectable by TEM.

The mechanical properties of pure PIM-6FDA-OH polyimide and PIM-6FDA-OH/ZIF-8 mixedmatrix membranes are shown in Table S1. PIM-6FDA-OH showed Young's modulus, tensile strength and elongation at break of $0.51 \mathrm{GPa}, 16.9 \mathrm{MPa}$ and 4.6\%, respectively. Young's modulus and tensile strength increased for MMMs containing up to $33 \mathrm{wt} \%$ ZIF-8, indicating good compatibility between PIM-6FDA$\mathrm{OH}$ and ZIF-8. At higher ZIF-8 loadings, tensile strength decreased significantly, most likely due to agglomeration of ZIF-8 particles in the MMMs. The elongation at break of the MMMs decreased continuously with increasing fraction of ZIF-8, specifically at the highest loading of 65 wt $\%$, demonstrating the mechanical stability limit of the MMMs of this study. 
a)
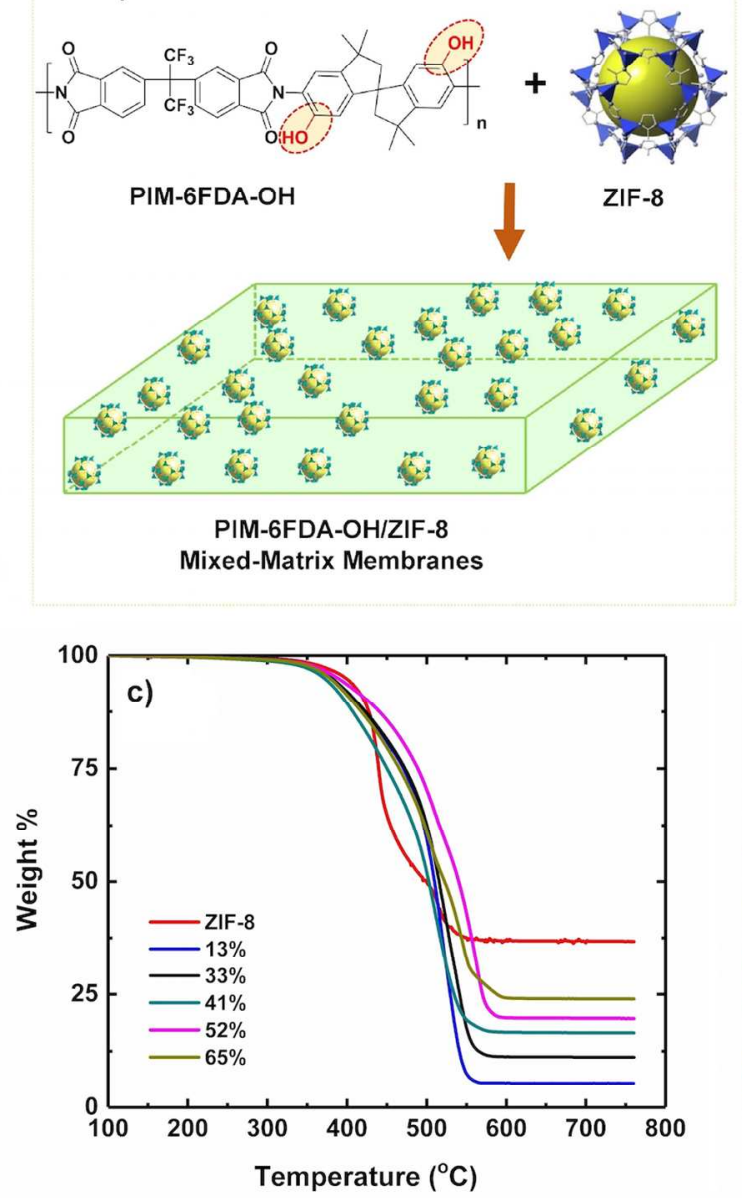

b)
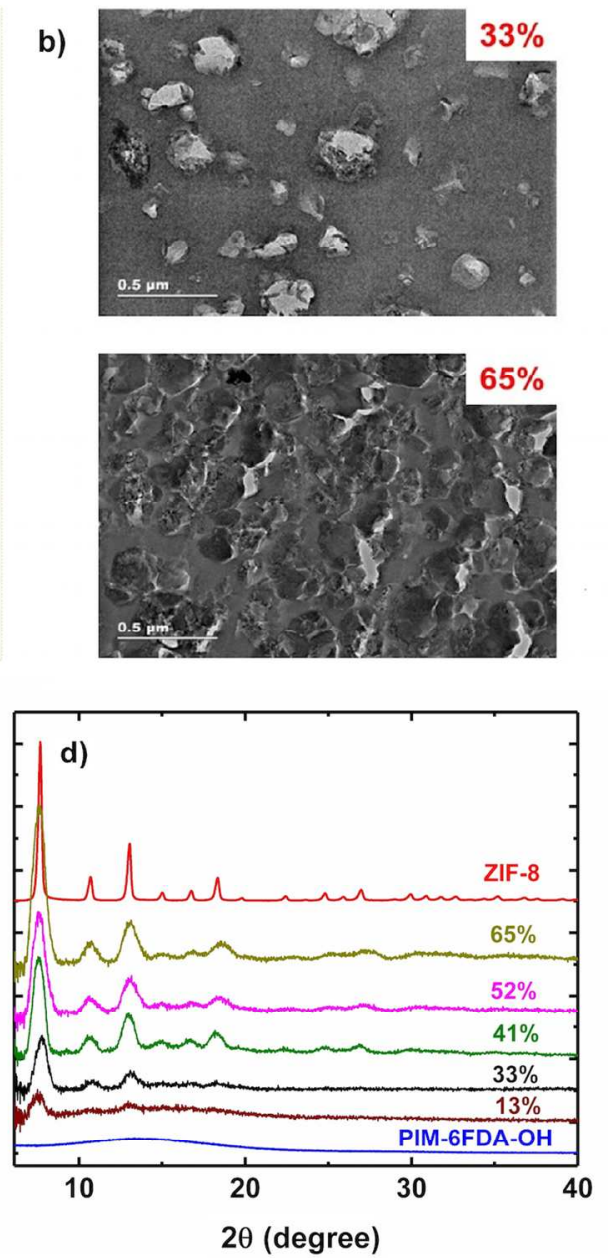

Figure 1. (a) Preparation of PIM-6FDA-OH/ZIF-8-based MMMs; b) TEM images of PIM-6FDA-OHbased MMMs containing 33 and 65 wt\% ZIF-8; c) TGA of the MMMs in air; d) XRD patterns of PIM6FDA-OH, ZIF-8 and PIM-6FDA-OH/ZIF-8 MMMs.

Combustion of the MMMs in air by heating up to $800{ }^{\circ} \mathrm{C}$ using TGA (Figure 1c) generated $\mathrm{ZnO}$ residue, which was used to calculate the weight content of ZIF-8 in the MMMs. ${ }^{23,24}$ Only small deviations of the ZIF-8 content in the originally prepared casting suspensions were observed in the MMM films (Table S2). XRD patterns of PIM-6FDA-OH/ZIF-8 MMMs (Figure 1d) demonstrated that all characteristic diffraction peaks of pure ZIF-8 were retained in the MMMs, indicating that the crystal structure of the embedded ZIF-8 was not altered by the membrane preparation protocol and the subsequent heat treatment at $250{ }^{\circ} \mathrm{C}$ to completely dry and activate the MMMs. In general, interfacial 
incompatibility of fillers dispersed in a continuous polymer matrix can be identified by a lower experimental MMM density relative to the calculated MMM values based on pure polymer and filler densities and their MMM weight fractions..$^{22,31,32}$ Lower MMM density can result from either large macroscopic interfacial defects or increased polymer matrix chain spacing induced by filler nanoparticles. ${ }^{32}$ In both cases, MMM permeability is expected to increase combined with a reduction in permselectivity due to loss of the size-sieving diffusion selectivity. The experimental densities of the PIM-6FDA-OH/ZIF-8-based MMMs were essentially identical to the theoretical values calculated based on pure-component density values by: $\rho_{\mathrm{MMM}}=\rho_{\mathrm{P}} \Phi_{\mathrm{P}}+\rho_{\mathrm{ZIF}-8} \Phi_{\mathrm{ZIF}-8}$, where $\rho_{\mathrm{P}}$ and $\rho_{\mathrm{ZIF}-8}$ are pure-component densities of PIM-6FDA-OH $\left(\rho=1.30 \mathrm{~g} \mathrm{~cm}^{-3}\right)$ and ZIF-8 $\left(\rho=0.95 \mathrm{~g} \mathrm{~cm}^{-3}\right)$, respectively; $\Phi_{\mathrm{P}}$ and $\Phi_{\mathrm{ZIF}-8}$ are the volume fractions of polymer and ZIF-8 (Table S2, Figure S5). This result implies that that the purecomponent gas transport properties of ZIF-8 and PIM-6FDA-OH were preserved in the MMMs, which is of utmost importance for the estimation of gas permeabilities and selectivities of the MMMs by the Maxwell model (Table S3 and Table S4). ${ }^{7,18}$

Interaction between ZIF-8 and PIM-6FDA-OH was qualitatively identified by FT-IR and XPS spectra, as shown in Figure 2. The C-N band of pure PIM-6FDA-OH and ZIF-8 are located at 1100 and $1146 \mathrm{~cm}^{-1}$, respectively (Figure 2a). A continuous decrease in C-N band intensity and gradual shifts in peak positions from 1100 to $1105 \mathrm{~cm}^{-1}$ and 1137 to $1140 \mathrm{~cm}^{-1}$ for the MMMs at different ZIF-8 loadings compared to pure polymer PIM-6FDA-OH, all indicative of favorable materials interaction, were observed after normalization of the MMM FT-IR spectra with respect to the C-N band of pure ZIF-8.

Further evidence for the interaction between PIM-6FDA-OH and ZIF-8 was provided by comparing their XPS spectra with PIM-6FDA-OH/ZIF-8 MMMs (Figure S6). High resolution Zn 2p spectra of ZIF-8 show the binding energies for $\mathrm{Zn} 2 \mathrm{p}_{3 / 2}$ and $\mathrm{Zn} 2 \mathrm{p}_{1 / 2}$ core levels centered at 1021.3 and $1044.4 \mathrm{eV}$, respectively. However, clear shifts to higher energy values (about $0.6 \mathrm{eV}$ ) for both $\mathrm{Zn} 2 \mathrm{p}_{3 / 2}$ and $\mathrm{Zn} 2 \mathrm{p}_{1 / 2}$ core levels in the MMM sample containing $33 \mathrm{wt} \%$ ZIF-8 suggest the change of local chemical bonding environment around $\mathrm{Zn}$ resulting from the interaction between ZIF-8 and PIM-6FDA-OH (Figure 2b). 
Moreover, high resolution XPS spectrum of N 1s (Figure 2c) in the MMM sample (centered at $400.3 \mathrm{eV}$ ) reveals a major shift of $1.7 \mathrm{eV}$ to a higher energy value compared to pure ZIF-8 (398.6 eV, Figure 2c), and a minor shift $(\sim 0.2 \mathrm{eV})$ to a lower energy value compared to PIM-6FDA-OH $(400.4 \mathrm{eV})$, indicating possible electron transfer from ZIF-8 to PIM-6FDA-OH in the MMM. Such effects are most likely induced by the $\mathrm{N} \cdots \mathrm{H}-\mathrm{O}$ hydrogen bonding between the nitrogen moiety of the 2 -methylimidiazole in ZIF-8 and the hydroxyl groups in PIM-6FDA-OH (Figure 2d).
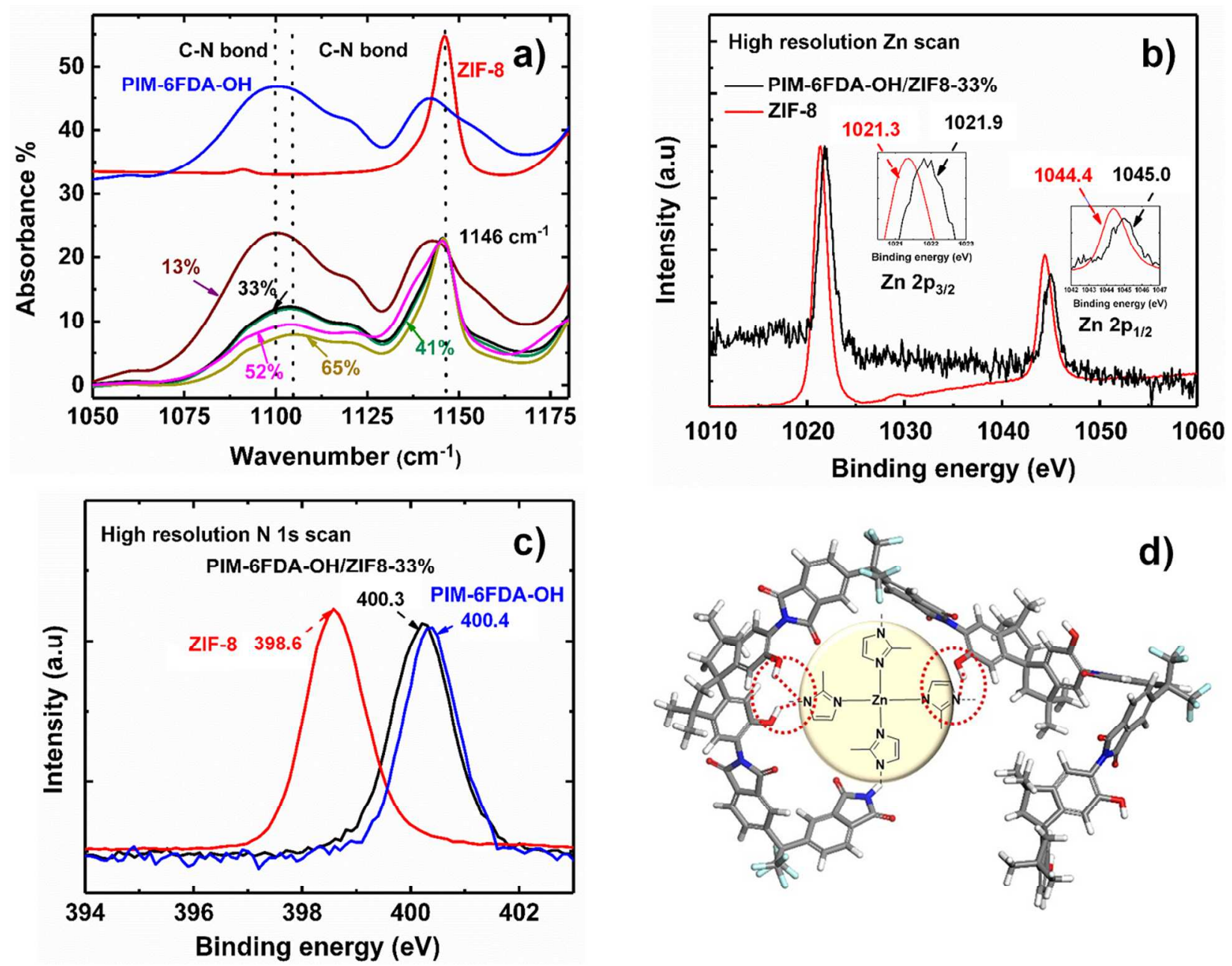

Figure 2. a) FT-IR spectra of PIM-6FDA-OH, ZIF-8 and PIM-6FDA-OH/ZIF-8 mixed-matrix membranes in the range of C-N bond from 1050 to $1175 \mathrm{~cm}^{-1}$; b) Zn 2p1/2 and 2p3/2 XPS spectra of ZIF8 and PIM-6FDA-OH/ZIF-8 (33 wt\%) mixed-matrix membrane; c) N 1s XPS spectra of PIM-6FDA-OH, ZIF-8 and PIM-6FDA-OH/ZIF-8 (33 wt\%) mixed-matrix membrane; d) Possible mechanism for shifting of $\mathrm{Zn}$ - and N-signal of the MMM. 
Gas Separation Performance. The $\mathrm{C}_{3} \mathrm{H}_{6}$ and $\mathrm{C}_{3} \mathrm{H}_{8}$ pure-gas permeation properties of the PIM6FDA-OH/ZIF-8 mixed-matrix membranes measured at 2 bar and $35{ }^{\circ} \mathrm{C}$ are reported in Table S2; the intrinsic properties of pristine PIM-6FDA-OH ${ }^{28}$ and pure $\mathrm{ZIF}-8^{30}$ are listed for comparison. A propylene permeability of $\sim 130$ barrer and $\mathrm{C}_{3} \mathrm{H}_{6} / \mathrm{C}_{3} \mathrm{H}_{8}$ selectivity of $\sim 100$ were calculated from recently reported experimental permeation data of $2 \mu \mathrm{m}$-thick pure ZIF-8 composite membranes. ${ }^{30}$ Clearly, an increase in ZIF-8 loading resulted in significant enhancement in $\mathrm{C}_{3} \mathrm{H}_{6}$ permeability and $\mathrm{C}_{3} \mathrm{H}_{6} / \mathrm{C}_{3} \mathrm{H}_{8}$ selectivity in the PIM-6FDA-OH-based MMMs. The propylene permeability soared 11-fold from 3.5 barrer for the pristine PIM-6FDA-OH to 38 barrer for the MMM containing $65 \mathrm{wt} \%$ ZIF-8. Furthermore, an increase in puregas $\mathrm{C}_{3} \mathrm{H}_{6} / \mathrm{C}_{3} \mathrm{H}_{8}$ selectivity from 30 to 43 was observed, which is the highest selectivity of all MMMs reported to date for propylene/propane separation.

Propylene and propane sorption coefficients were determined by gravimetric sorption experiments at 2 bar and $35^{\circ} \mathrm{C}$ and the diffusion coefficients were then obtained from the relationship $D=P / S$ (Table S2). The $\mathrm{C}_{3} \mathrm{H}_{6}$ solubility coefficient increased from 0.22 for PIM-6FDA-OH to $0.52 \mathrm{~cm}^{3}(\mathrm{STP}) \mathrm{cm}^{-3}$ $\mathrm{cmHg}^{-1}$ for the MMM containing $65 \mathrm{wt} \%$ ZIF-8 combined with an even more significant $\sim 4$-fold increase in the $\mathrm{C}_{3} \mathrm{H}_{6}$ diffusion coefficient from $0.16 \times 10^{-8}$ to $0.73 \times 10^{-8} \mathrm{~cm}^{2} \mathrm{~s}^{-1}$. As expected from their pure-gas solubility properties, incorporation of ZIF-8 to PIM-6FDA-OH had essentially no effect on the $\mathrm{C}_{3} \mathrm{H}_{6} / \mathrm{C}_{3} \mathrm{H}_{8}$ solubility selectivity of $\sim 1.1$ Hence, the boost in $\mathrm{C}_{3} \mathrm{H}_{6} / \mathrm{C}_{3} \mathrm{H}_{8}$ permselectivity of the MMMs can be attributed almost entirely to enhanced $\mathrm{C}_{3} \mathrm{H}_{6} / \mathrm{C}_{3} \mathrm{H}_{8}$ diffusion selectivity due to the strong molecular sieving effect of the ultramicroporous ZIF-8 filler (Table S2).

The pure-gas performance of the PIM-6FDA-OH/ZIF-8 mixed-matrix membranes is compared to the propylene/propane trade-off curve in Figure 3a. Clearly, their performance is located significantly above the upper bound line and higher than the calculated theoretical performance of hyperthetical mixedmatrix membranes based on polymer matrices located on the upper bound line with 30,40 , and 50 wt $\%$ loading of ZIF-8 with $\mathrm{PC}_{3} \mathrm{H}_{6}=130$ barrer and $\alpha \mathrm{C}_{3} \mathrm{H}_{6} / \mathrm{C}_{3} \mathrm{H}_{8}=100$ (Table S3) using the Maxwell equation (Data and calculations are included in the Supporting Information, Table S3). 

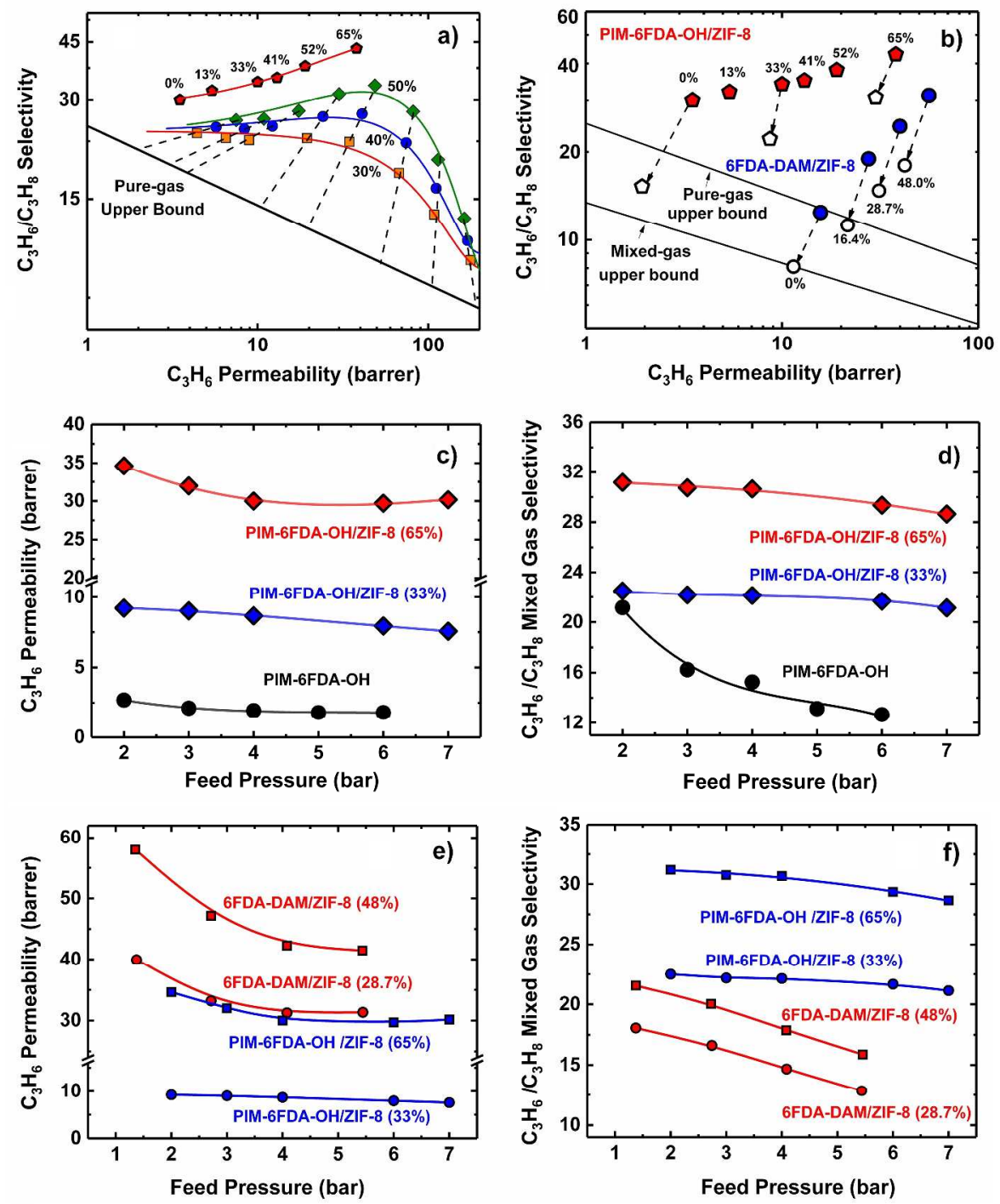

Figure 3 a) Pure-gas $\mathrm{C}_{3} \mathrm{H}_{6}$ permeability and $\mathrm{C}_{3} \mathrm{H}_{6} / \mathrm{C}_{3} \mathrm{H}_{8}$ selectivity for PIM-6FDA-OH/ZIF- 8 membranes with different ZIF-8 loadings and the theoretical performance of mixed-matrix membranes with 30 vol\% (red), 40 vol\% (blue) and 50 vol\% (green) ZIF-8 loading dispersed in polymers located on the 2003 polymer upper bound line ${ }^{29}$; b) Pure- and mixed-gas $\mathrm{C}_{3} \mathrm{H}_{6} / \mathrm{C}_{3} \mathrm{H}_{8}$ separation properties of PIM-6FDA$\mathrm{OH} / \mathrm{ZIF}-8$ and 6FDA-DAM/ZIF- ${ }^{23}$ mixed-matrix membranes at 2 bar; c) Pressure dependence of $\mathrm{C}_{3} \mathrm{H}_{6}$ permeability of PIM-6FDA-OH and MMMs containing 33 and $65 \mathrm{wt} \%$ ZIF-8; d) Pressure dependence of $\mathrm{C}_{3} \mathrm{H}_{6} / \mathrm{C}_{3} \mathrm{H}_{8}$ selectivity of PIM-6FDA-OH and MMMs containing 33 and $65 \mathrm{wt} \%$ ZIF-8; e) Pressure dependence of $\mathrm{C}_{3} \mathrm{H}_{6}$ permeability of PIM-6FDA-OH/ZIF-8 MMMs and 6FDA-DAM-based MMMs 
containing 28.7 and 48 wt\% ZIF-8; f) Pressure dependence of $\mathrm{C}_{3} \mathrm{H}_{6} / \mathrm{C}_{3} \mathrm{H}_{8}$ selectivity of PIM-6FDAOH/ZIF-8 MMMs and 6FDA-DAM-based MMMs containing 28.7 and 48 wt\% ZIF-8.

In their seminal work, Zhang and Koros reported excellent propylene/propane separation performance of ZIF-8-based MMMs using a non-hydroxyl-functionalized 6FDA-DAM (1,3,5-trimethyldiaminobenzene) polyimide as the polymer matrix with the maximum loading of $48 \mathrm{wt} \%{ }^{23}$ Based on pure-gas experiments the 6FDA-DAM (48 wt\%) MMM displayed a propylene permeability of 56.2 barrer with $\mathrm{C}_{3} \mathrm{H}_{6} / \mathrm{C}_{3} \mathrm{H}_{8}$ selectivity of 31 . In a similar approach using a 9:1 copolymer matrix of 6FDA-TMPD (2,3,5,6tetramethyl-p-phenylenediamine) and 6FDA-DABA (3,5-diaminobenzoic acid) containing 41.9 wt.\% ZIF-8, Askari and Chung reported pure-gas MMM properties of $\mathrm{PC}_{3} \mathrm{H}_{6}=47.3$ barrer and $\mathrm{C}_{3} \mathrm{H}_{6} / \mathrm{C}_{3} \mathrm{H}_{8}$ selectivity of 27.4 measured at 3.5 bar and $35^{\circ} \mathrm{C} .{ }^{24}$ Because of its higher intrinsic $\mathrm{C}_{3} \mathrm{H}_{6} / \mathrm{C}_{3} \mathrm{H}_{8}$ selectivity (30 vs. 12.4) and higher ZIF-8 loading capacity (65 vs 48 wt.\%), PIM-6FDA-OH-based MMMs exhibited better overall pure-gas performance than the 6FDA-DAM-derived MMM analogues (Figure 3b). Mixedgas permeation properties measured at 4 bar pressure and $35{ }^{\circ} \mathrm{C}$ with a 50:50 propylene/propane feed showed a drop in propylene permeability and $\mathrm{C}_{3} \mathrm{H}_{6} / \mathrm{C}_{3} \mathrm{H}_{8}$ selectivity for both membrane types (open symbols, Figure 3b), most likely due to competitive sorption effects. ${ }^{10,28,33}$ Nevertheless, the highest loading PIM-6FDA-OH/ZIF-8 (65 wt\%) membrane maintained excellent mixed-gas performance with a propylene permeability of 30 barrer and $\mathrm{C}_{3} \mathrm{H}_{6} / \mathrm{C}_{3} \mathrm{H}_{8}$ selectivity of $\sim 31$.

Previous work showed that the $\mathrm{C}_{3} \mathrm{H}_{6} / \mathrm{C}_{3} \mathrm{H}_{8}$ selectivity of pure ZIF-8 membranes was severely pressure dependent and declined rapidly with increasing pressure when tested under mixed-gas conditions (Figure S7) due to a decrease in propylene permeability and, more importantly, a significant increase in propane permeability. ${ }^{30,34}$ This result indicated that pure ZIF-8 is susceptible to plasticization-like effects possibly due to stretching of its highly size-selective aperture by sorption of large, condensable hydrocarbons..$^{30,34}$ The mixed-gas propylene permeability (Figure 3c) and $\mathrm{C}_{3} \mathrm{H}_{6} / \mathrm{C}_{3} \mathrm{H}_{8}$ selectivity (Figure 3d) pressure dependence was evaluated up to 7 bar for the pristine PIM-6FDA-OH polyimide and the MMMs containing 33 and $65 \mathrm{wt} \%$ ZIF-8, respectively. Interestingly, more stable propylene/propane mixed-gas 
performance was observed for the MMMs. The PIM-6FDA-OH/ZIF-8 MMMs demonstrated outstanding plasticization resistance with only $\sim 6-8 \%$ decrease in mixed-gas selectivity by increasing the feed pressure from 2 to 7 bar (Figure 3d). Even at a feed pressure of 7 bar (p/psat $\sim 0.5$ ) membranes with ZIF8 loading of 33 and $65 \mathrm{wt} \%$ exhibited mixed-gas selectivity of 21.1 and 28.7 , respectively (Table S5). On the other hand, the mixed-gas $\mathrm{C}_{3} \mathrm{H}_{6} / \mathrm{C}_{3} \mathrm{H}_{8}$ selectivity of the pristine PIM-6FDA-OH membrane decreased by $40 \%$ from 21 to 12.7 by raising the feed pressure from 2 to 7 bar (Figure 3d). The more significant decrease in mixed-gas $\mathrm{C}_{3} \mathrm{H}_{6} / \mathrm{C}_{3} \mathrm{H}_{8}$ selectivity of the pure PIM-6FDA-OH membrane could have resulted from more significant effects of polymer plasticization on gas transport properties as compared to the OH-functionalized ZIF-8-based MMMs. Over the same pressure range, the non-functionalized 6FDADAM/ZIF-8 mixed-matrix membranes also displayed a larger relative decline in permeability and selectivity than the PIM-6FDA-OH/ZIF-8 membranes (Figure 3e and Figure 3f). Our results suggest that the strong molecular interaction of the hydroxyl-functionalized polyimide and nitrogen-containing ZIF-8 by $\mathrm{N} \cdots \mathrm{O}-\mathrm{H}$ hydrogen bonding stabilized the structural flexibility of the individual components in the MMMs. Consequently, our approach provides a new platform for development of highly plasticizationresistant mixed-matrix membranes including imidazolate-derived metal-organic frameworks other than ZIF-8.

\section{CONCLUSIONS}

The growing need for more energy-efficient gas separations has dramatically increased interest using membrane systems. In this work, a series of high-performance, plasticization-resistant mixed-matrix membranes for propylene/propane separation was successfully developed based on ultramicroporous ZIF8 and a dihydroxyl-functionalized polyimide (PIM-6FDA-OH). Hitherto, unmatched mixed-gas propylene/propane performance was demonstrated for MMMs containing up to $65 \mathrm{wt} \% \mathrm{ZIF}-8$ under challenging high-pressure feed conditions. Strong interactions between the $\mathrm{OH}$-functionalized polyimide and the N-containing imidazolate framework by hydrogen bonding were detected by FTIR and XPS spectra and resulted in formation of defect-free, high-performance MMMs. Our approach provides 
therefore a promising route for investigation of MMMs based on alternative $\mathrm{OH}$-functionalized polymers and tailor-made ZIFs for other energy-intensive separations, such as ethylene/ethane and butane isomer purification.

\section{ASSOCIATED CONTENT}

\section{Supporting Information}

The Supporting Information is available free of charge on the ACS Publications website at DOI:

Mechanical properties, ZIF-8 nitrogen adsorption isotherm, ZIF-8 particles size distribution, TEM, XPS, Maxwell model predictions, experimental gas transport data.

\section{AUTHOR INFORMATION \\ Corresponding Author \\ *E-mail: ingo.pinnau@kaust.edu.sa (I.P.). \\ ORCID}

Ingo Pinnau: 0000-0003-3040-9088

\section{Notes}

The authors declare no competing financial interest.

\section{Acknowledgements}

This publication is based upon work supported by the King Abdullah University of Science and Technology (KAUST). Xiaohua Ma and Ramy Swaidan contributed equally to this work

\section{REFERENCES}

(1) Zimmermann, H. Propene, in: Ullmann's Encyclopedia of Industrial Chemistry. Weinheim: WileyVCH Verlag GmbH \& Co., pp.1-18, 2013.

(2) Eldridge, R. B. Olefin/Paraffin Separation Technology: a Review. Ind. Eng. Chem. Res. 1993, 32, 2208-2212.

(3) Wei, X. The 8th Sino-US Joint Conference of Chemical Engineering, Olefin/Paraffin Separation by Membranes: an Industrial Perspective. Shanghai, China, October, 2015. 
(4) Christopher, C. C. E.; Dutta, A.; Farooq, S.; I. Karimi, A. Process Synthesis and Optimization of Propylene/Propane Separation Using Vapor Recompression and Self-Heat Recuperation. Ind. Eng. Chem. Res. 2017, 56, 14557-14564.

(5) Koros, W. J.; Lively, R. P. Water and Beyond: Expanding the Spectrum of Large $\square$ Scale Energy Efficient Separation Processes. AICHE J. 2012, 58, 2624-2633.

(6) Sholl, D. S.; Lively, R. P. Seven Chemical Separations to Change the World. Nature 2016, 532, 435437.

(7) Koros, W. J.; Zhang, C. Materials for Next-Generation Molecularly Selective Synthetic Membranes. Nat. Mater. 2017, 16, 289-297.

(8) Galizia, M.; Chi, W. S; Smith, Z. P.; Merkel, T. C.; Baker, R. W.; Freeman, B. D. 50th Anniversary Perspective: Polymers and Mixed Matrix Membranes for Gas and Vapor Separation: A Review and Prospective Opportunities. Macromolecules 2017, 50, 7809-7843.

(9) Tanaka, K.; Taguchi, A.; Hao, J. Q.; Kita, H.; Okamoto, K.-I. Permeation and Separation Properties of Polyimide Membranes to Olefins and Paraffins. J. Membr. Sci. 1996, 121, 197-207.

(10) Staudt-Bickel, C.; Koros, W. J. Olefin/Paraffin Gas Separations with 6FDA-Based Polyimide Membranes. J. Membr. Sci. 2000, 170, 205-214.

(11) Park, K. S.; Ni, Z.; Cote, A. P.; Choi, J. Y.; Huang, R. D.; Uribe-Romo, F. J.; Chae, H. K.; O'Keeffe, M.; Yaghi, O. M. Exceptional Chemical and Thermal Stability of Zeolitic Imidazolate Frameworks. $P$. Natl. Acad. Sci. 2006, 103, 10186-10191.

(12) Fairen-Jimenez, D.; Moggach, S. A.; Wharmby, M. T.; Wright, P. A.; Parsons, S.; Düren, T. Opening the Gate: Framework Flexibility in ZIF-8 Explored by Experiments and Simulations. J. Am. Chem. Soc. 2011, 133, 8900-8902.

(13) Bennett, T. D.; Cheetham, A. K.; Fuchs, A. H.; Coudert, F. X. Interplay Between Defects, Disorder and Flexibility in Metal-Organic Frameworks. Nat. Chem. 2017, 9, 11-16.

(14) Zhang, C.; Lively, R. P.; Zhang, K.; Johnson, J. R.; Karvan, O.; Koros, W. J. Unexpected Molecular Sieving Properties of Zeolitic Imidazolate Framework-8. J. Phys. Chem. Lett. 2012, 3, 2130-2134.

(15) Pan, Y. C.; Li, T.; Lestari, G.; Lai, Z. P. Effective Separation of Propylene/Propane Binary Mixtures by ZIF-8 Membranes. J. Membr. Sci. 2012, 390-391, 93-98.

(16) Zimmerman, C. M.; Singh, A.; Koros, W. J. Tailoring Mixed Matrix Composite Membranes for Gas Separations. J. Membr. Sci. 1997, 137, 145-154.

(17) Chung, T. S.; Jiang, L. Y.; Li, Y.; Kulprathipanja, S. Mixed Matrix Membranes (MMMs) Comprising Organic Polymers with Dispersed Inorganic Fillers for Gas Separation. Prog. Polym. Sci., 2007, 32, 483-507. 
(18) Dong, G.; Li, H.; Chen, V. Challenges and Opportunities for Mixed-Matrix Membranes for Gas Separation. J. Mater. Chem. A. 2013, 1, 4610-4630.

(19) Tanh Jeazet, H. B.; Staudt, C.; Janiak, C. Metal-Organic Frameworks in Mixed-Matrix Membranes for Gas Separation. Dalton Trans. 2012, 41, 14003-14027.

(20) Ordonez, M. J. C.; Balkus, K. J.; Ferraris, J. P.; Musselman, I. H. J. Membr. Sci. 2010, 361, $28-37$.

(21) Song, Q.; Nataraj, S. K.; Roussenova, M. V.; Tan, J. C.; Hughes, D. J.; Li, W.; Bourgoin, P.; Alam, M. A.; Cheetham, A. K.; Al-Muhtaseb, S. A.; Sivaniah, E. Energy Environ. Sci. 2012, 5, 8359-8369.

(22) Bushell, A. F.; Attfield, M. P.; Mason, C. R.; Budd, P. M.; Yampolskii, Y.; Starannikova, L.; Rebrov, A.; Bazzarelli, F.; Bernardo, P.; Jansen, J. C.; Lanc, M.; Friess, K.; Shantarovich, V.; Gustov, V. Isaeva, V. Gas Permeation Parameters of Mixed Matrix Membranes Based on the Polymer of Intrinsic Microporosity PIM-1 and the Zeolitic Imidazolate Framework ZIF-8. J. Membr. Sci. 2013, 427, 48-62.

(23) Zhang, C.; Dai, Y.; Johnson, J. R.; Karvan, O.; Koros, W. J. High Performance ZIF-8/6FDA-DAM Mixed Matrix Membrane for Propylene/Propane Separations. J. Membr. Sci. 2012, 389, 34-42.

(24) Askari, M.; Chung, T.-S. Natural Gas Purification and Olefin/Paraffin Separation Using Thermal Cross-Linkable Co-Polyimide/ZIF-8 Mixed Matrix Membranes. J. Membr. Sci. 2013, 444, 173-183.

(25) Lin, R. J.; Hernandez, B. V.; Ge, L.; Zhu Z. H. Metal Organic Framework Based Mixed Matrix Membranes: an Overview on Filler/Polymer Interfaces. J. Mater. Chem. A 2018, 6, 293-312.

(26) Wang, Z. G.; Wang, D.; Zhang, S. X.; Hu, L.; Jin, J. Interfacial Design of Mixed Matrix Membranes for Improved Gas Separation Performance. Adv. Mater. 2016, 28, 3399-3405.

(27) Ma, X.; Swaidan, R.; Belmabkhout, Y.; Zhu, Y. H.; Litwiller, E.; Jouiad, M.; Pinnau, I.; Han, Y. Synthesis and Gas Transport Properties of Hydroxyl-Functionalized Polyimides with Intrinsic Microporosity. Macromolecules 2012, 45, 3841-3849.

(28) Swaidan, R. J.; Ma, X.; Litwiller, E.; Pinnau, I. Enhanced Propylene/Propane Separation by Thermal Annealing of an Intrinsically Microporous Hydroxyl-Functionalized Polyimide Membrane. J. Membr.

Sci. 2015, 495, 235-241.

(29) Burns, R. L.; Koros, W. J. Defining the Challenges for $\mathrm{C}_{3} \mathrm{H}_{6} / \mathrm{C}_{3} \mathrm{H}_{8}$ Separation Using Polymeric Membranes. J. Membr. Sci. 2003, 211, 299-309.

(30) Sheng, L. Q.; Wang, C. Q.; Yang, F.; Xiang, L.; Huang, X. J.; Yu, J.; Zhang, L. X.; Pan, Y. C.; Li, Y. S. Enhanced $\mathrm{C}_{3} \mathrm{H}_{6} / \mathrm{C}_{3} \mathrm{H}_{8}$ Separation Performance on MOF Membranes through Blocking Defects and Hindering Framework Flexibility by Silicone Rubber Coating. Chem. Commun. 2017, 53, 7760-7763.

(31) Merkel, T. C.; Freeman, B. D.; Spontak, R. J.; He, Z.; Pinnau, I.; Meakin, P.; Hill, A. J.

Ultrapermeable, Reverse-Selective Nanocomposite Membranes. Science 2002, 296, 519-522.

(32) Ahn, J.; Chung, W.-J.; Pinnau, I.; Song, J.; Du, N.; Robertson, G. P.; Guiver, M. D. Gas Transport Behavior of Mixed-Matrix Membranes Composed of Silica Nanoparticles in a Polymer of Intrinsic 
Microporosity (PIM-1). J. Membr. Sci. 2010, 346, 280-287.

(33) Das, M.; Koros, W. J. Performance of 6FDA-6FpDA Polyimide for Propylene/Propane Separations. J. Membr. Sci. 2010, 365, 399-408.

(34) Yu, J; Pan, Y.; Wang, C.; Lai., Z. ZIF-8 Membranes with Improved Reproducibility Fabricated from Sputter-Coated ZnO/Alumina Supports. Chem. Eng. Sci. 2016, 141, 119-124. 


\section{For Table of Contents only}

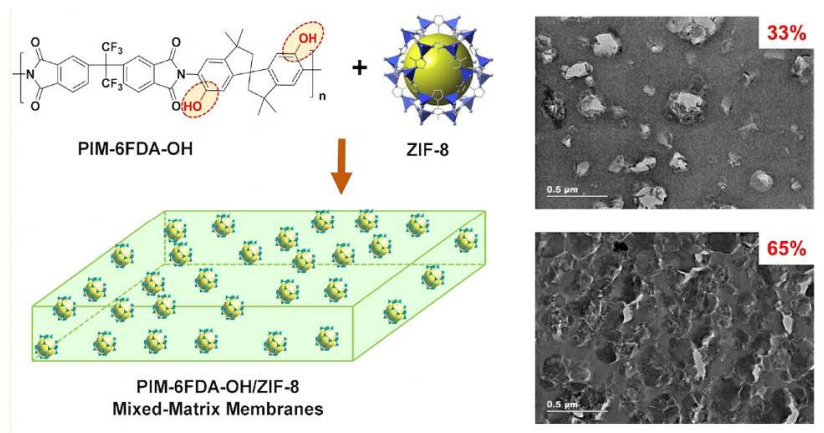


a)
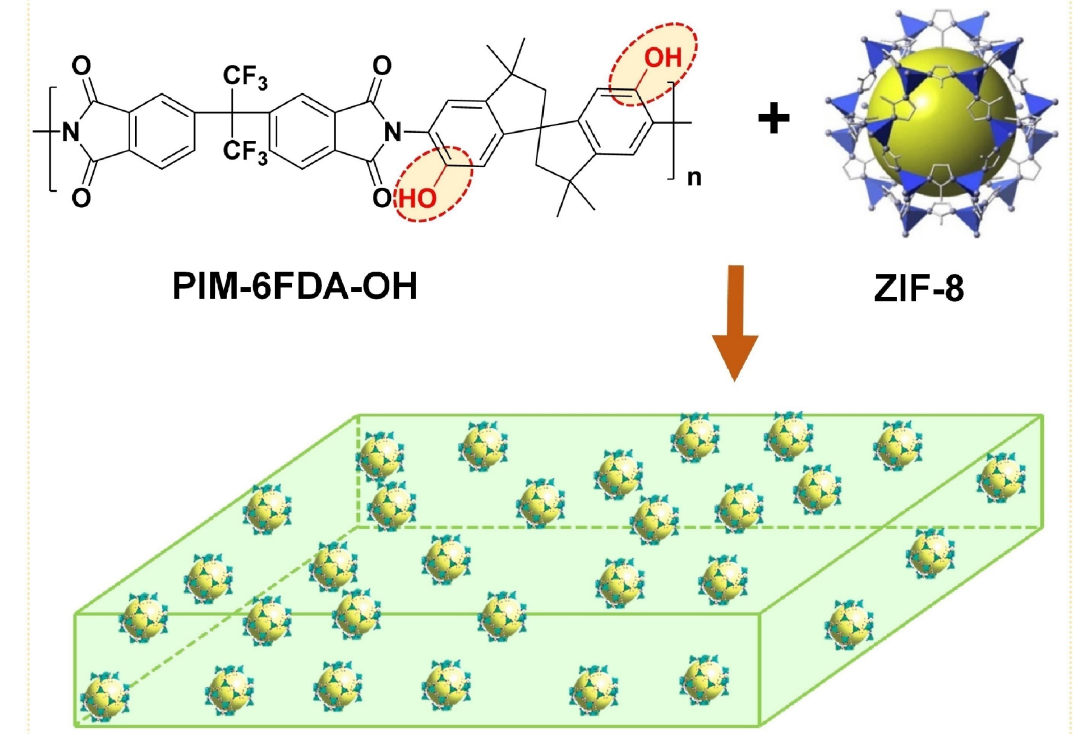

PIM-6FDA-OH/ZIF-8

Mixed-Matrix Membranes

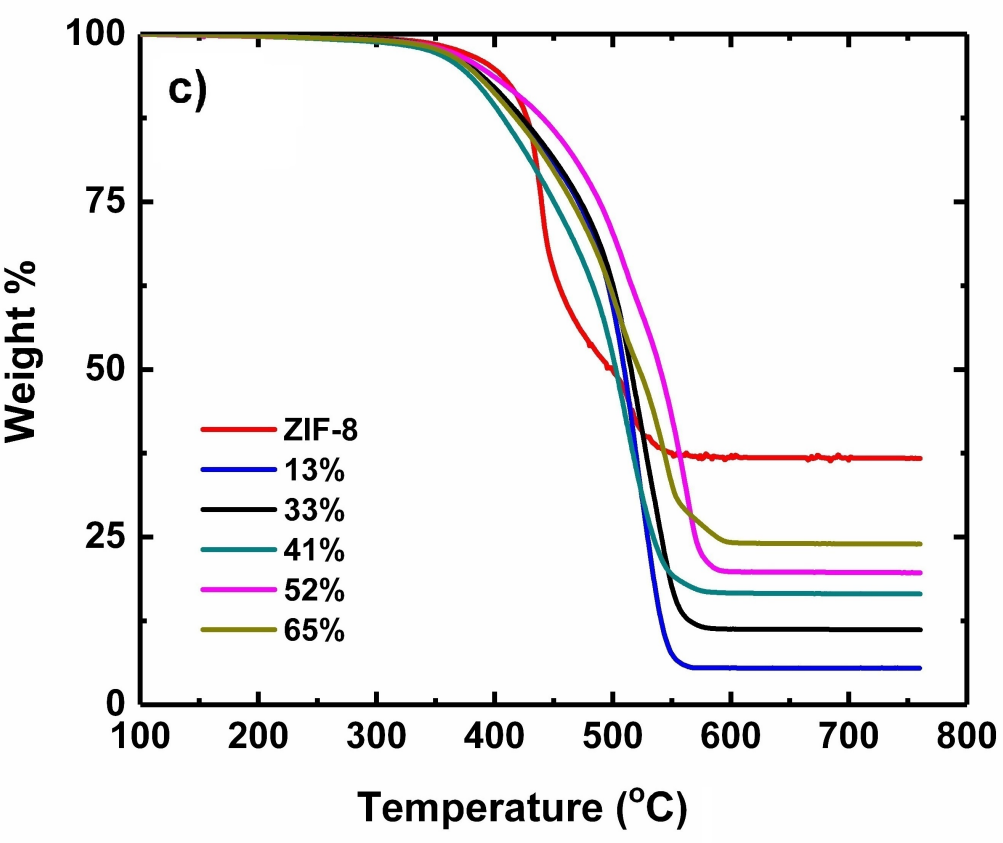

b)
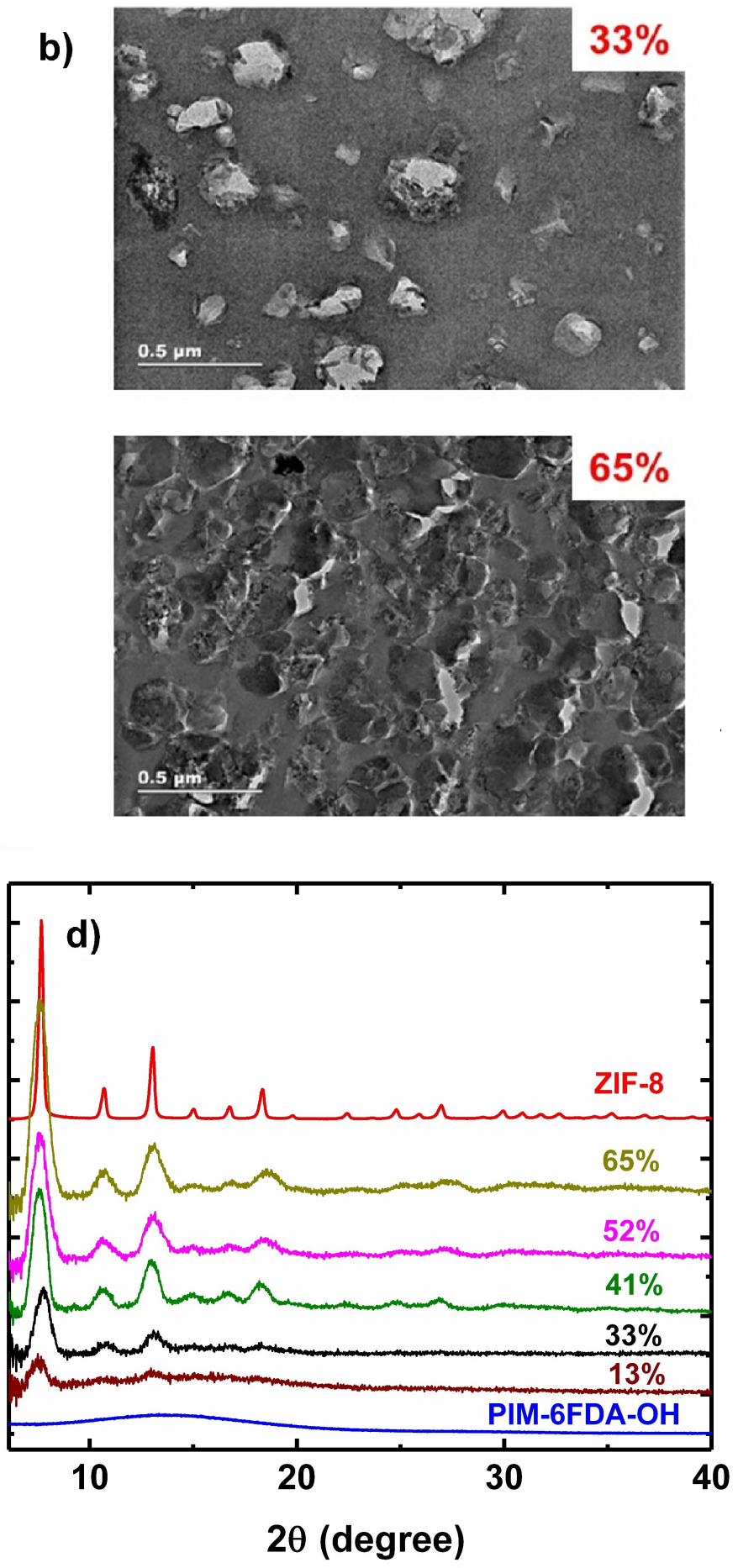

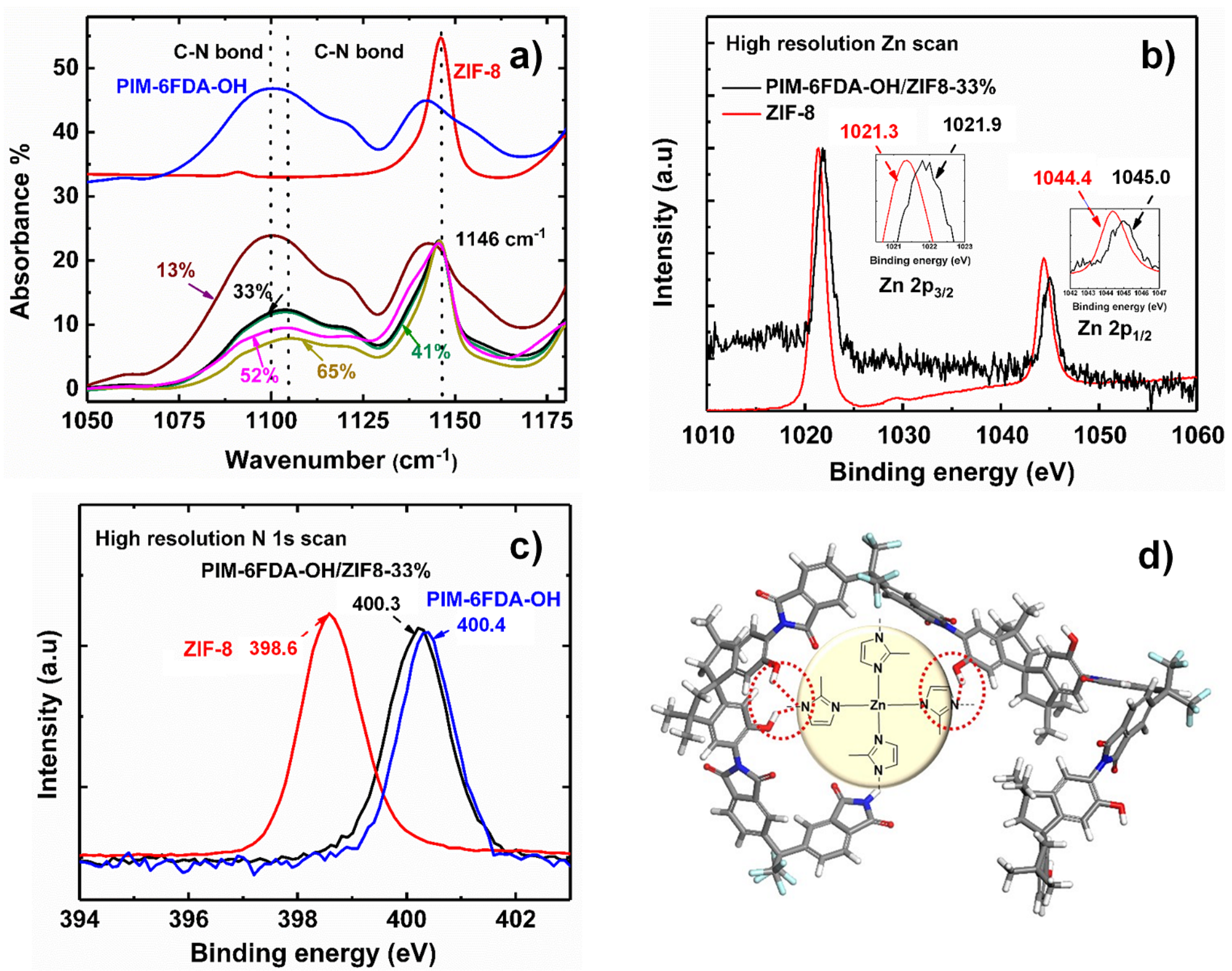

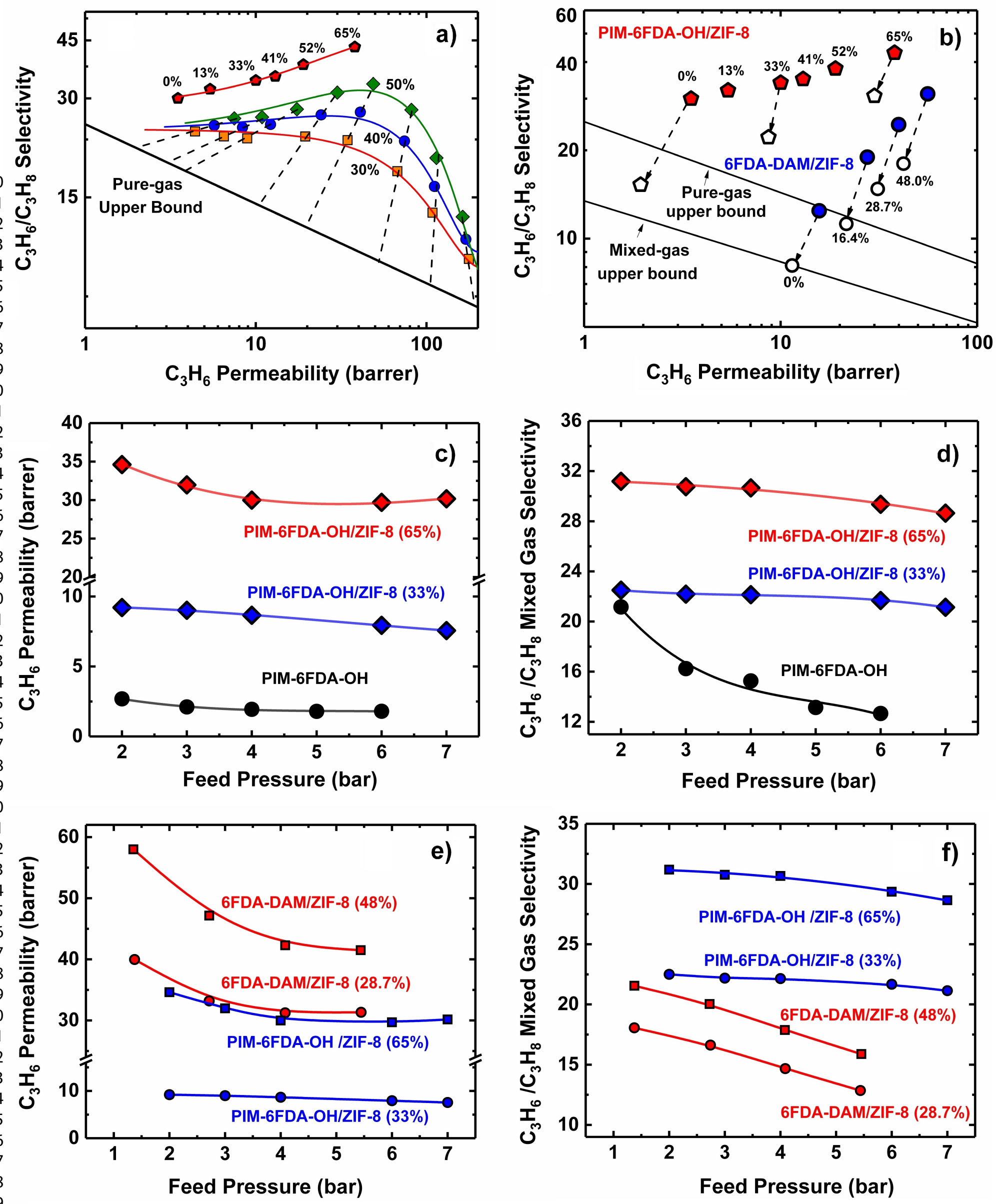

ACS Paragon Plus Environment 